\title{
Time Value of Commercial Product Returns
}

Gilvan C. Souza ${ }^{1}$, V. Daniel R. Guide Jr. ${ }^{2}$, Luk N. Van Wassenhove ${ }^{3}$, Joseph D. Blackburn ${ }^{4}$

${ }^{1}$ Robert H. Smith School of Business, University of Maryland, College Park MD 20742 USA

${ }^{2}$ Smeal College of Business, The Pennsylvania State University, University Park PA 16802 USA

${ }^{3}$ INSEAD, Boulevard de Constance, 77305 Fontainebleau, France

${ }^{4}$ Owen School of Management, Vanderbilt University, Nashville TN 37203 USA

\begin{abstract}
Manufacturers and their distributors must cope with an increased flow of returned products from their customers. The value of commercial product returns, which we define as products returned for any reason within 90 days of sale, now exceeds US $\$ 100$ billion annually in the US. Although the reverse supply chain of returned products represents a sizeable flow of potentially recoverable assets, only a relatively small fraction of the value is currently extracted by manufacturers; a large proportion of the product value erodes away due to long processing delays. Thus, there are significant opportunities to build competitive advantage from making the appropriate reverse supply chain design choices. In this paper, we present a simple queuing network model that includes the marginal value of time to identify the drivers of reverse supply chain design. We illustrate our approach with specific examples from two companies in different industries and then examine how industry clockspeed generally affects the choice between an efficient and a responsive returns network.
\end{abstract}

\section{Introduction}

Manufacturers and their distributors must cope with an increased flow of returned products from their customers. The value of commercial product returns, which we define as products returned for any reason within 90 days of sale, now exceeds US \$100 billion annually (Stock, Speh and Shear 2002). Although the reverse supply chain of returned products represents a sizeable flow of potentially recoverable assets, only a small fraction is currently extracted by manufacturers. A large proportion of the product value erodes away in the returns process. Most returns processes in place 
today were developed for an earlier environment in which return rates were low and the value of the asset stream was insignificant. Returns processes were typically designed for cost efficiency where collection networks minimized logistics costs and the need for managerial oversight. For example, Stock, Speh and Shear (2002) describe Sears' cost-effective transportation network serving three central returns processing centers.

Although cost-efficient logistics processes may be desirable for collection and disposal of products when return rates are low and profit margins are comfortable, this approach can actually limit a firm's profitability in today's business environment. The design of processes driven by a narrow operational cost focus can create time delays that limit the options available for reuse. These limited product disposition options can lead to substantial losses in product value recovery. This is typically the case for short life cycle, time-sensitive products where these losses can exceed $30 \%$ of product value. There is a need for design strategies for product returns that emphasize asset recovery in addition to operating costs, and that need motivates this research.

We consider the problem of how to design and manage the reverse supply chain to maximize net asset value recovered from the flow of returned products. Unlike forward supply chains, no principles of design strategy for returns processing have been established. Blackburn, Guide, Souza and Van Wassenhove (2004) hypothesize that the marginal value of time can be used to help managers design the right reverse supply chain. Their hypotheses are supported by case studies of several reverse supply chains. We evaluate alternative reverse supply chain designs using queuing network models capturing the effects on costs and revenues. Our alternative network designs are derived from two sources: observations of emerging practices in returns processing and the research on design strategies for forward supply chains.

Our models are built and validated using data collected through in-depth studies of the returns processes at Hewlett-Packard Company (HP) and Robert Bosch Tool Corporation (Bosch). These two firms' product return environments exhibit significant differences in processing and delay costs, 
and we show that these should lead to alternative network designs, offering useful insights into what drives these decisions. We subsequently use these two cases as a basis for sensitivity analysis and test the generality of our insights.

This paper is organized as follows. In $\S 2$, we review the relevant literature. In $\S 3$, we present an overview of the product returns system for two manufacturers, HP and Bosch, which serves as a motivation for the model. In $\S 4$, we present the model, and theoretical results. In $\S 5$, we study ways to improve network responsiveness. In $\S 6$, we analyze a partially decentralized network for handling product returns. In $\S 7$, we apply the results to $\mathrm{HP}$ and Bosch, using empirical data from these manufacturers. Finally, we conclude in $\S 8$.

\section{Literature Review}

Although manufacturers have a growing interest in extracting value from commercial product returns, there has been little research on how to design the reverse supply chain for this purpose. However, extensive research has been conducted on managing product return flows for the recovery of products at their end-of-use (EOU) or end-of-life (EOL), where products are prevented from entering the waste stream via value and materials recovery systems. Fleischmann (2001), Guide (2000) and Guide and Van Wassenhove (2003) offer comprehensive reviews of the remanufacturing,

reverse logistics, and closed-loop supply chain research on EOU/EOL returns processes. Most of these studies focus on cost-efficient recovery and/or meeting environmental standards. This literature has focused on operating issues (e.g., inventory control, scheduling, materials planning) and the logistics of product recovery. Few papers take a business perspective of how to make product returns operations profitable (see Guide and Van Wassenhove 2001 for a discussion and Guide, Teunter and Van Wassenhove 2003 for a modeling example).

Much of the previous research on commercial product returns documents the return rates of different product categories and the cost of processing returns. This research finds that return rates 
vary widely by product category, by season and across global markets. For example, product return percentages can vary from 5-9\% for hard goods and up to $35 \%$ for high fashion apparel. Return percentages are also typically much higher for Internet and catalogue sales. Other research has found that, due to differences in customer attitudes and retailers' return policies, the proportion of returned product tends to be considerably higher in North America. Many retailers in the United States permit returns for any reason within several months of sale. Return policies have been much more restrictive in Europe and, consequently, return rates were markedly lower. However, return rates are rising in Europe rapidly due to new EU policies governing Internet sales, and the entry of powerful US-based resellers. Additionally, companies have seen an increase in commercial returns disguised as defects from large resellers in the UK (Helbig 2002). Recent studies reported in the trade literature also reveal that returns may cost as much as three to four times the cost of outbound shipments (Andel and Aichlmayr 2002). Although these reports have raised management's awareness of the problem of product returns, the issue of how to extract more value from the returns stream has been largely ignored.

From a marketing perspective, research examines how returns policies affect consumer purchase probability and return rates. Wood (2001) found that more lenient policies tended to increase product returns, but that the increase in sales was sufficient to create a positive net sales effect. Other research has focused on the problem of setting returns policy between a manufacturer and a reseller and the use of incentives to control the returns flow (Padmanabhan and Png 1997 1995, Pasternack 1985, Davis, Gerstner and Hagerty 1995, Tsay 2001). Choi, Li and Yan (2004) study the effect of an e-marketplace on returns policy in which internet auctions are used to recover value from the stream of product returns.

\section{Supply Chain Design Strategy}

A number of researchers have contributed to the development of design strategy for forward supply chains and our models are motivated by this work (Swaminathan and Tayur 2003, Fisher 
1997, Lee and Whang 1999, Lee and Tang 1997, Feitzinger and Lee 1997). We are able to confirm a set of design principles for reverse supply chains. We observe that a (cost) efficient returns network equates to a centralized structure and a responsive network equates to a decentralized one (Fisher 1997). However, we find that in reverse supply chain design, it is early, not delayed, product differentiation that determines profitability.

\section{Closed-Loop Queuing Networks}

We use closed-loop queuing network models to evaluate alternative reverse supply chain design strategies. Because we are concerned with net asset value recovered, it is important to model the returns process as part of a closed-loop system that integrates the flows of the traditional forward chain with the reverse chain. Conceptually, our model is similar to the queuing model that Toktay, Wein and Zenios (2000) use to analyze a specific problem in the remanufacturing of disposable cameras.

\section{Valuing Time in Supply Chains}

A significant difference between our model and previous research on reverse supply chains is that we explicitly capture the cost of lost product value due to time delays at each stage of the returns process. Studies of time-based competition (Blackburn 1991) have demonstrated that faster response in business processes can be a source of competitive advantage, and other studies have shown how to quantify the effect of time delays in traditional make-to-stock supply chains (Blackburn 2001). In his book Clockspeed, Fine (1998) shows that the effects of speed vary across industries and product categories, and he uses these concepts to link supply chain strategies to product architecture. This earlier work provides the motivation for our models that specifically incorporate the cost of time delays and its effect on asset recovery. 


\section{Commercial Returns at HP and Bosch}

Customers may return products for a variety of reasons (see Tables 1 and 2), many of which may be classified as non-defective. We refer to these non-defective returns as new returns, since these are essentially unused products that may be resold after visual inspection and repackaging. HP estimates the cost of product returns at 2 percent of total outbound sales for North America alone (Davey 2001). Figure 1 shows the flow for product returns in generic terms.

\subsection{Case 1: Hewlett-Packard Inkjet Printers}

HP's product returns strategy is focused on recovering maximum value from the returns and developing capabilities that would put HP in a position of competitive advantage. HP's inkjet printer division handled over 50,000 returns per month in North America in 1999 (Davey 2001). The most recent trend estimates show a $20 \%$ increase. Inkjet printers have a relatively short lifecycle, with a new model being introduced every 18 months on average.

Products returned to the reseller are stored until transportation to the central HP returns depot outside Nashville, TN, where credit is issued. No hard data is available on how long the returned products spend waiting for transport at the reseller. This can vary drastically from reseller to reseller, but HP managers believe products could spend as long as 4 weeks when the returns are stored in areas where they are 'out-of-sight, out-of-mind' (Davey 2001).

Inkjet printers are delivered via truck and are unloaded and stored in holding areas at the depot to await disposition. The time required for transportation ranges from 6 to 13 days depending on the distance to be traveled. The receipt and credit issuance take an average of 4 days. After credit issuance, returns are sorted by product line. Inkjet printers are tested, evaluated, and sent to one of several facilities. All HP printers have an electronic counter that allows a technician to determine how many copies have been printed. 
Figure 1: Product returns process flows

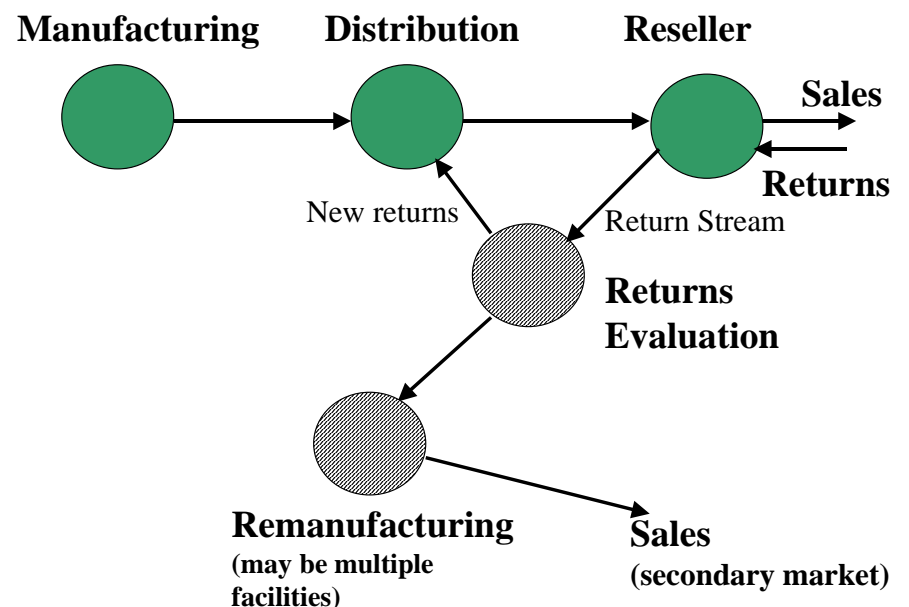

Table 1: Breakdown of reasons for commercial product returns of HP printers

\begin{tabular}{|l|l|l|l|}
\hline $\begin{array}{l}\text { Reason for } \\
\text { return }\end{array}$ & Description & $\begin{array}{l}\text { \% of } \\
\text { returns }\end{array}$ & Procedure after return \\
\hline Product defective & $\begin{array}{l}\text { A truly defective product - it simply } \\
\text { does not function as intended }\end{array}$ & $20.0 \%$ & $\begin{array}{l}\text { Product is tested, remanufactured (low } \\
\text { or high touch) and sold to a secondary } \\
\text { market (sell as remanufactured). }\end{array}$ \\
\hline Could not install & $\begin{array}{l}\text { The customer could not install the } \\
\text { product correctly. Box opened, but } \\
\text { product was never used. }\end{array}$ & $27.5 \%$ & $\begin{array}{l}\text { Product is tested for number of pages } \\
\text { printed; if this number is below a } \\
\text { threshold value, then the product is re- } \\
\text { boxed and shipped back to the forward } \\
\text { distribution center to be sold as new. } \\
\text { Otherwise it is shipped to appropriate } \\
\text { remanufacturing facility. }\end{array}$ \\
\hline $\begin{array}{l}\text { Performance not } \\
\text { compatible with } \\
\text { user needs }\end{array}$ & $\begin{array}{l}\text { The product did not meet the user's } \\
\text { needs. Print quality was too low, } \\
\text { printing speed was too slow, etc. }\end{array}$ & $40.0 \%$ \\
\hline $\begin{array}{l}\text { Convenience } \\
\text { returns }\end{array}$ & $\begin{array}{l}\text { The product was returned for a host of } \\
\text { reasons (remorse, rental, better price, } \\
\text { etc.) }\end{array}$ & $12.5 \%$ & \\
\hline
\end{tabular}

Presently, the average remanufacturing time is 40 days. All remanufactured HP inkjet printers are sold in secondary markets under the direction of a dedicated sales representative.

\subsection{Case 2: Robert Bosch Tool Corporation}

Bosch's Skil line is aimed at the consumer market. These tools are reasonably priced and have small profit margins due to the competitive nature of the market. The current product returns process is a result of the 90-day returns policy, which is meant to attract customers.

Customers return products directly to resellers. The life cycle of power tools currently averages 6 years. Table 2 shows the primary reasons customers return products (Wolman 2003). The reseller holds the returned tools in an RTV (return-to-vendor) cage. This inventory is held until a Bosch 
salesperson is available to perform disposition on the product. The period of time between receipt of product and disposition is again highly variable, depending on the workload of the salesperson, with times ranging from one to four weeks (Valenta 2002). The returned products are sent to Walnut Ridge, AR if a product is deemed to be a straightforward remanufacture and to Addison, IL if the problem appears to be more technical in nature. Products are transported in bulk via trucks to the appropriate remanufacturing facility. Products are diagnosed by technicians and remanufactured when possible. Products are discarded if reconditioning is not possible or likely to be very expensive. The reconditioned products are sold mainly to liquidators at an average of $15 \%$ below the retail price for the new product.

Table 2: Returns classifications for power tools

\begin{tabular}{|l|c|}
\hline \multicolumn{1}{|c|}{ Reason for return } & \multicolumn{1}{|c|}{$\begin{array}{c}\text { Percentage of returns } \\
\text { Consumer tools }\end{array}$} \\
\hline Product defective & $60 \%$ \\
\hline $\begin{array}{l}\text { Poor performance - does not meet } \\
\text { user expectations }\end{array}$ & $15 \%$ \\
\hline Improper marketing of tool & $10 \%$ \\
\hline Buyer remorse & $10 \%$ \\
\hline $\begin{array}{l}\text { Tool used for a specific purpose then } \\
\text { returned (rental) }\end{array}$ & $5 \%$ \\
\hline
\end{tabular}

\section{A Simple Analytical Model for the Time-Value of Product Returns}

We present an analytical model that computes the value of time in a closed-loop supply chain and provides closed-form expressions that allow a manager to quickly compute the value of reducing delays. In $§ 5$, we discuss specific actions aimed at reducing delays in the network.

Empirical evidence gathered at HP and Bosch suggests that the rate of commercial returns follows a curve similar to the product life cycle, shifted to the right in the time axis, with a long steady state period. Figure 2 shows the returns life cycle for an inkjet printer, which has a typical life cycle of 18 months; the steady state period varies from 7 to 13 months. For Bosch power tools, a typical life cycle is 6 years, with a steady state period of 5 years. In the ramp-up period of the life cycle, most returns are used for warranties (i.e., instead of repairing defective products in the field, 
the firm uses refurbished products originated from convenience returns to replace these defective products), whereas in the ramp-down period their primary use is for spare parts, after disassembly (Davey 2001).

We focus on profit maximization for the steady state period of the returns life cycle, due to the high volumes involved, the long time frame, and the primary use of returns in the steady state period for remanufacturing and sales at a secondary market. We model a closed-loop supply chain as shown in Figure 3, where the notation is defined in Table 3. The facilities in the closed-loop supply chain include factory, distribution center, retailer, customer, central evaluating facility for returns, remanufacturing, and the secondary market, where remanufactured products are sold. We represent facilities by nodes, and the flow of products through the nodes is indicated in Figure 3, and described in detail below. To avoid unnecessary confusion, our notation uses parentheses for grouping terms, and square brackets for denoting functions, e.g., $r(1-p)$ denotes $r$ times $(1-p)$, and $c[a]$ denotes $c$ as a function of $a$.

Similarly to Toktay, Wein and Zenios (2000), and for ease of exposition, we consider a single retailer. In $\$ 7$ we show how the model can be easily extended to multiple retailers when we apply it to HP. Also similarly to Toktay et al., nodes are modeled as either M/M/1 or M/G/œ queues. We choose to model the facilities and processes of interest (those on the return path-return at retailers, evaluation of returns, and remanufacturing) as $\mathrm{M} / \mathrm{M} / 1$ queues to capture the significant congestion effects observed in practice. The processes on the forward network (factory, distributor and retailer sales), which realize little congestion, are modeled as $\mathrm{M} / \mathrm{G} / \infty$ queues. In addition, there are transportation delays $\tau_{i j}$ between each pair of nodes $i$ and $j$ in Figure 3, except to and from the customer.

Time $t=0$ is defined as the beginning of the steady state period for returns (sales are already in steady state at that time). Time $t=T$ is the end of steady state for sales and returns (whichever is earlier). Thus all queues are in steady state for the period of analysis. The flow rates between each 
pair of nodes $\lambda_{i j}$ are defined in Figure 3, i.e., $\lambda_{f d}=\lambda+(1-p) \lambda_{r}, \lambda_{d s}=\lambda_{s c}=\lambda+\lambda_{r}, \lambda_{c r}=\lambda_{r e}=\lambda_{r}$, $\lambda_{e m}=\lambda_{m 2}=(1-p) \lambda_{r}$, and $\lambda_{e d}=p \lambda_{r}$.

Consistent with empirical data obtained at HP and Bosch, we assume for both new and remanufactured products exponential price decay functions, i.e. $P[t]=P[0] e^{-\alpha t}$ and $P_{m}[t]=P_{m}[0] e^{-\alpha_{m} t}$, and exponential variable cost decay functions, i.e. $v[t]=v[0] e^{-\phi t}$, and $v_{m}[t]=v_{m}[0] e^{-\phi_{m} t}$. The continuous-time decay parameters ( $\alpha$ and $\alpha_{m}, \phi$ and $\left.\phi_{m}\right)$ may or may not be equal. All decay parameters can be viewed as a measure of industry clockspeed (see, e.g. Williams 1992, Mendelson and Pillai 1999).

Figure 2: Returns lifecycle for a typical inkjet printer

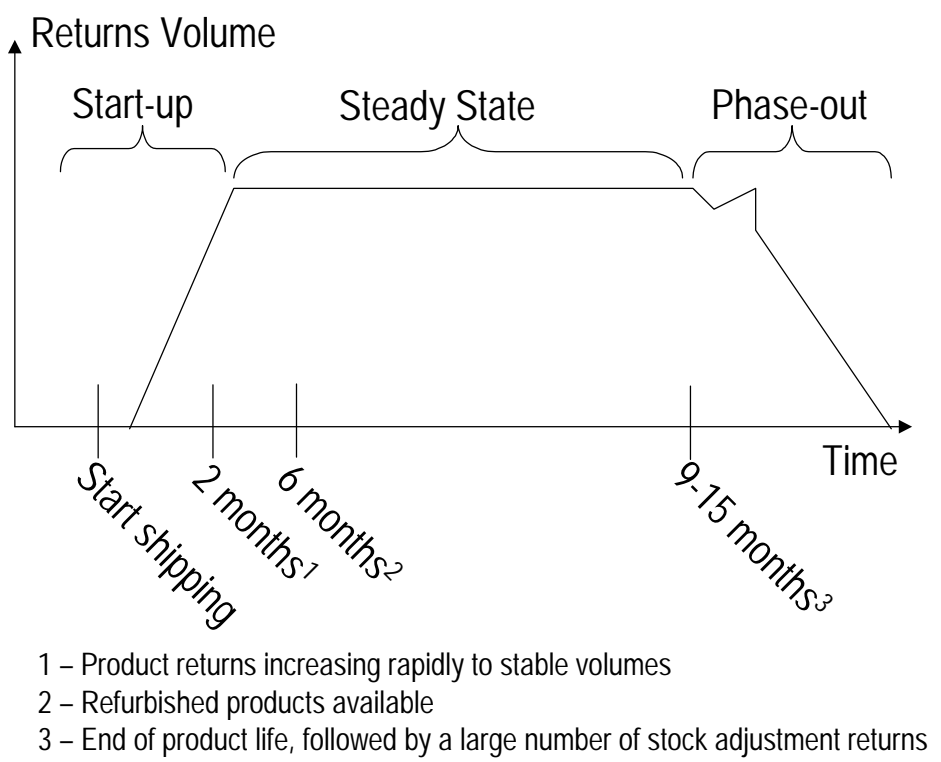

There are handling costs for processing returns where $h_{i}\left[\mu_{i}\right]$ is the handling cost per unit if facility $i$ ( $i=r$ for retailer and $i=e$ for evaluating facility) operates at processing rate $\mu_{i}$. Transportation and handling costs, however, are assumed constant over time. This is because the decay in prices and variable costs is primarily related to material and product value erosion, which does not hold for transportation and handling costs. All cash flows are discounted at a continuous discount factor $\beta$, which represents the firm's opportunity cost of capital (i.e., time value of money).

For tractability, we make two assumptions:

Assumption 4-1: New returns are only returned once. That is, a new return only goes through the cycle in Figure 3 once. 
Assumption 4-2: The actual flow times in the network of Figure 3 are approximated by their expected values $W_{i j}$.

Assumption 4-1 is reasonable because new returns constitute a relatively small percentage of all product sales, as we will see later in the numerical examples. Assumption 4-2 is necessary for tractability, because the delays in the network are random variables with complicated gamma-type distributions. We comment on Assumption 4-2 later.

Table 3: Notation

\begin{tabular}{|l|l|}
\hline$i, j$ & $\begin{array}{l}\text { Subscripts for nodes: } f \text { (factory), } d \text { (distributor), } s \text { (retailer sales), } r \text { (retailer returns), } c \\
\text { (customer), } e \text { (central evaluating facility), } m \text { (remanufacturing), 2 (sales outlet at secondary } \\
\text { market) }\end{array}$ \\
\hline$\lambda$ & Net new sales rate at the primary market \\
\hline$\lambda_{r}$ & Total steady state return rate \\
\hline$p$ & Proportion of new returns from total returns \\
\hline$\mu_{i}$ & Average processing rate of products (new/returns) at node $i$ \\
\hline$\lambda_{i j}$ & Product flow rate between nodes $i$ and $j$ \\
\hline$\tau_{i j}$ & Average transportation time between nodes $i$ and $j$ \\
\hline$W_{i j}$ & $\begin{array}{l}\text { Expected flow time between the beginning of processing at node } i \text { and end of processing at } \\
\text { node } j\end{array}$ \\
\hline$\alpha$ & Continuous-time price decay at primary market (i.e., $\%$ price decay per unit time) \\
\hline$\alpha_{m}$ & Continuous-time price decay at secondary market \\
\hline$\beta$ & Continuous-time discount rate \\
\hline$\phi$ & Continuous-time variable production cost decay parameter \\
\hline$\phi_{m}$ & Continuous-time remanufacturing cost decay parameter \\
\hline$P[t]$ & Unit price for new product at primary market at time $t$ \\
\hline$P_{m}[t]$ & Unit price for remanufactured product at secondary market at time $t ;$ \\
\hline$v[t]$ & Variable production cost at time $t$ \\
\hline$v_{m}[t]$ & Variable remanufacturing cost at time $t$ \\
\hline$c_{i j}$ & Unit transportation cost between nodes $i$ and $j$ \\
\hline$h_{i}\left[\mu_{i}\right]$ & Handling cost per unit at node $i$ as a function of processing rate at node $i ; i \in\{e, r\}$ \\
\hline$\pi[t]$ & Expected profit rate at time $t$ \\
\hline$\Pi$ & Total expected discounted profit over steady-state period \\
\hline
\end{tabular}

The sequence of events is as follows (see Figure 3):

- Time $t$ : the factory produces $\lambda+(1-p) \lambda_{r}$ units at a per unit cost $v[t]$. These units are shipped to the distributor, where they are joined by $p \lambda_{r}$ new returns (produced at time $t-W_{\text {loop }}$, where $W_{\text {loop }}$ is the expected delay through the loop for the network shown in Figure 3), and then transported to the retailer. 
- Time $t+W_{f s}$ : the retailer sells $\lambda+\lambda_{r}$ units at a per unit price $P\left[t+W_{f s}\right]$. After a sojourn time with the customer, $\lambda_{r}$ units are returned to the retailer, where they wait until they are shipped to the evaluating facility for sorting and credit issuance.

- Time $t+W_{f s}+W_{c e}$ : after sorting, the manufacturer issues a credit of $P\left[t+W_{f s}\right]$ (selling price) for each of the $\lambda_{r}$ returns to the retailer. New returns $p \lambda_{r}$ are shipped to the forward distribution center; non-new returns $(1-p) \lambda_{r}$ are shipped to the remanufacturing facility.

- Time $t+W_{f s}+W_{c m}$ : non-new returns $(1-p) \lambda_{r}$ are remanufactured at a per unit cost $v_{m}\left[t+W_{f s}+W_{c m}\right]$, and then shipped to the secondary market.

- Time $t+W_{f s}+W_{c 2}:(1-p) \lambda_{r}$ remanufactured products are sold at the secondary market at a per unit price $P_{m}\left[t+W_{f s}+W_{c 2}\right]$.

Figure 3: Closed-loop supply chain model

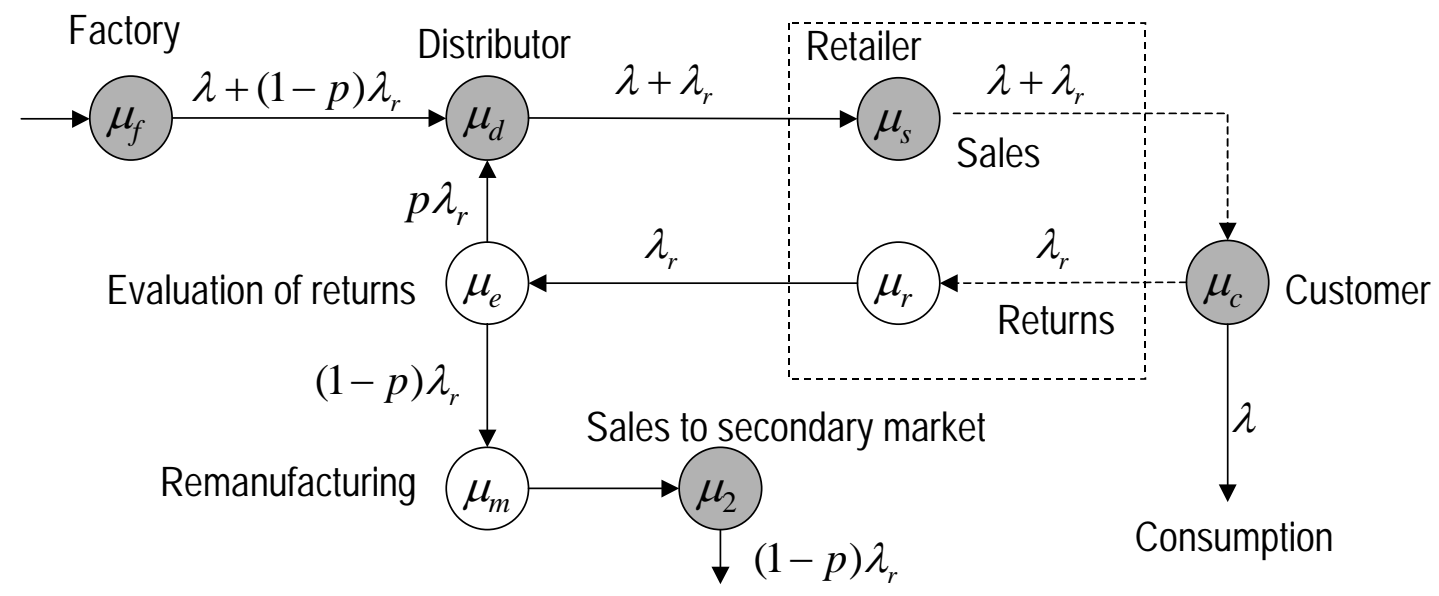

Note: Blank and shaded nodes are modeled as $\mathrm{M} / \mathrm{M} / 1$ and $\mathrm{M} / \mathrm{G} / \infty$ queues, respectively

The expected delays $W_{i j}$ are computed as follows:

$$
\begin{gathered}
W_{f s}=1 / \mu_{f}+\tau_{f d}+1 / \mu_{d}+\tau_{d s}+1 / \mu_{s}, \\
W_{c e}=\frac{1}{\mu_{c}}+\frac{1}{\mu_{r}-\lambda_{r}}+\tau_{r e}+\frac{1}{\mu_{e}-\lambda_{r}}, \\
W_{c m}=W_{c e}+\tau_{e m}+\frac{1}{\mu_{m}-(1-p) \lambda_{r}},
\end{gathered}
$$




$$
\begin{gathered}
W_{c 2}=W_{c m}+\tau_{m 2}+1 / \mu_{2}, \text { and } \\
W_{\text {loop }}=W_{c e}+\tau_{e d}+1 / \mu_{d}+\tau_{d s}+1 / \mu_{s} .
\end{gathered}
$$

The expected profit rate at time $t$ for the existing network is:

$$
\begin{aligned}
\pi[t] & =\left(\lambda+\lambda_{r}\right) P\left[t+W_{f s}\right]-\left(\lambda+(1-p) \lambda_{r}\right) v[t]-\lambda_{r} P\left[t+W_{f s}\right] e^{-\beta W_{c e}} \\
& -p \lambda_{r}\left(v\left[t-W_{\text {loop }}\right]-v[t]\right)+(1-p) \lambda_{r}\left(P_{m}\left[t+W_{f s}+W_{c 2}\right]-v_{m}\left[t+W_{f s}+W_{c m}\right]\right) \\
& -\sum_{(i, j) \text { in net }} \lambda_{i j} c_{i j}-\lambda_{r} h_{e}\left[\mu_{e}\right]-\lambda_{r} h_{r}\left[\mu_{r}\right],
\end{aligned}
$$

The terms in (6) represent sales revenue for $\lambda+\lambda_{r}$ products sold at a unit price $P\left[t+W_{f s}\right]$ at the retailer, variable production cost at the factory at time $t$, credit issued for $\lambda_{r}$ returns $W_{c e}$ time units after they were sold at time $t+W_{f s}$, difference in variable costs for new returns (i.e. new returns were produced at $W_{\text {loop }}$ time units before other non-returned products and hence at a higher cost), unit margin for remanufactured products (unit price $P_{m}\left[t+W_{f s}+W_{c 2}\right]$ minus unit production cost $\left.v_{m}\left[t+W_{f s}+W_{c m}\right]\right)$, sum of transportation costs across all network arcs, handling costs at the evaluating facility and retailer, respectively.

The total expected discounted profit over the steady state period is given by $\Pi=\int_{0}^{T} \pi[t] e^{-\beta t} d t$, and can be easily derived, resulting in

$$
\begin{aligned}
\Pi= & \lambda\left(\tilde{P} e^{-\alpha W_{f s}}-\tilde{v}\right)+\lambda_{r} \tilde{P} e^{-\alpha W_{f s}}\left(1-e^{-\beta W_{c e}}\right)-p \tilde{v} \lambda_{r}\left(e^{\phi W_{\text {loop }}}-1\right) \\
& +(1-p) \lambda_{r}\left(\tilde{P}_{m} e^{-\alpha_{m}\left(W_{f s}+W_{c 2}\right)}-\tilde{v}_{m} e^{-\phi_{m}\left(W_{f s}+W_{c m}\right)}-\tilde{v}\right) \\
& -\sum_{(i, j)} \lambda_{i j} \tilde{c}_{i j}-\lambda_{r} \tilde{h}_{r}\left[\mu_{r}\right]-\lambda_{r} \tilde{h}_{e}\left[\mu_{e}\right]
\end{aligned}
$$

where, for notational convenience, we define the total discounted (including discounting and timedecay) revenue and cost parameters over $T$, denoted with tildes, as $\tilde{P}=P[0]\left(1-e^{-(\alpha+\beta) T}\right) /(\alpha+\beta)$,

$$
\begin{aligned}
& \tilde{v}=v[0]\left(1-e^{-(\phi+\beta) T}\right) /(\phi+\beta), \quad \tilde{v}_{m}=v_{m}[0]\left(1-e^{-\left(\phi_{m}+\beta\right) T}\right) /\left(\phi_{m}+\beta\right), \\
& \tilde{P}_{m}=P_{m}[0]\left(1-e^{-\left(\alpha_{m}+\beta\right) T}\right) /\left(\alpha_{m}+\beta\right), \tilde{c}_{i j}=c_{i j}\left(1-e^{-\beta T}\right) / \beta, \text { and } \tilde{h}_{i}[\cdot]=h_{i}[\cdot]\left(1-e^{-\beta T}\right) / \beta .
\end{aligned}
$$

The terms in (7) represent the net margin for (net) new products sales (revenues are "discounted" by the delay between production and sale), the "interest" gained by the manufacturer as 
a result of returns (credit of returns to retailer is issued later than sale), the difference in variable costs for new returns, the margin for remanufactured products, transportation and handling cost.

For the remainder of the analysis, we introduce, for tractability, an approximation: Assumption 4-3: Approximate $e^{-\alpha W_{i j}} \approx 1-\alpha W_{i j}$; similarly for $e^{\alpha_{m} W_{i j}}, e^{\phi_{m} W_{i j}}, e^{\phi W_{i j}}$, and $e^{\beta W_{i j}}$.

Assumption 4-3 is reasonable because for real-life parameters $\alpha W_{i j}<<1$ (similarly for $\alpha_{m}, \phi, \phi_{m}$, and $\beta$ - — this approximation implies a maximum error of $0.5 \%$ for the numerical examples of $\S 7$. We do not use an approximation for $\tilde{P}, \tilde{v}, \tilde{P}_{m}, \tilde{v}_{m}, \tilde{c}_{i j}$ and $\tilde{h}_{i}$ above because $T$ is considerably larger than any delay $W_{i j}$ in the network; thus $\alpha T>>\alpha W_{i j}$.

We now comment on Assumption 4-2. Consider an M/M/1 queue with arrival rate $\lambda$ and processing rate $\mu$; revenue per completed unit is $P[t]=P[0] e^{-\alpha t}$. The flow time $X$ follows an exponential distribution with mean $1 /(\mu-\lambda)$. The total expected discounted revenue over $[0, T]$ is $\Pi$ $=\lambda E_{X}\left\{\int_{0}^{T} P[t+X] e^{-\beta t} d t\right\}=\lambda P[0] \int_{t=0}^{T} \int_{x=0}^{\infty} e^{-\alpha(t+x)}(\mu-\lambda) e^{-(\mu-\lambda) x} e^{-\beta t} d x d t=\lambda \tilde{P}\left(1-\frac{\alpha}{\alpha+\mu-\lambda}\right) . \quad$ Under Assumption 4-2 and Assumption 4-3, $\Pi \approx \lambda \tilde{P}(1-\alpha W)=\lambda \tilde{P}\left(1-\frac{\alpha}{\mu-\lambda}\right)$; again, this is a very good approximation for realistic values of $\alpha$ (maximum error of $0.5 \%$ for the parameter values considered in the numerical examples here).

After regrouping the terms, (7) becomes.

$$
\begin{aligned}
\Pi & \approx \lambda(\tilde{P}-\tilde{v})+(1-p) \lambda_{r}\left(\tilde{P}_{m}-\tilde{v}_{m}-\tilde{v}\right)-\sum_{(i, j)} \lambda_{i j} \tilde{c}_{i j}-\lambda_{r} \tilde{h}_{r}\left[\mu_{r}\right]-\lambda_{r} \tilde{h}_{e}\left[\mu_{e}\right] \\
& -\left(\tau_{e d}+1 / \mu_{d}+\tau_{d s}+1 / \mu_{s}\right) p \lambda_{r} \tilde{v} \phi-W_{f s}\left\{\lambda \tilde{P} \alpha+(1-p) \lambda_{r}\left(\tilde{P}_{m} \alpha_{m}-\tilde{v}_{m} \phi_{m}\right)\right\} \\
& -W_{c e} \lambda_{r}\left\{-(\tilde{P} \beta-p \tilde{v} \phi)+(1-p)\left(\tilde{P}_{m} \alpha_{m}-\tilde{v}_{m} \phi_{m}\right)\right\} \\
& -\left(\tau_{e m}+\frac{1}{\mu_{m}-(1-p) \lambda_{r}}\right)(1-p) \lambda_{r}\left(\tilde{P}_{m} \alpha_{m}-\tilde{v}_{m} \phi_{m}\right)-\left(\tau_{m 2}+\frac{1}{\mu_{2}}\right)(1-p) \lambda_{r} \tilde{P}_{m} \alpha_{m}
\end{aligned}
$$

An analysis of (8) allows for an easy visualization for the sources of revenues and costs in the network, as well as the monetary effects of network delays. The first row indicates the steady state expected discounted profit without accounting for delays of new and returned products in the 
network: new product margins, remanufactured product margins, transportation and handling costs. Equation (8) reveals that this base expected profit is decreased by the delays in the network:

(i) The delay of new returns from production until sale (they are delayed by the loop shown in Figure 3). Thus, a one-day increase in $\tau_{e d}$ decreases expected profit by $p \lambda_{r} \tilde{v} \phi$, corresponding to the difference in variable production costs. Delays in other components of the loop also affect new products, as explained in (ii) below.

(ii) The delay of new products to reach the consumer $W_{f s}$. Considering (1) and (8), a one-day increase in the path between factory and distributor $\left(1 / \mu_{f}\right.$ or $\left.\tau_{f d}\right)$ decreases expected profit by $\lambda \tilde{P} \alpha+(1-p) \lambda_{r}\left(\tilde{P}_{m} \alpha_{m}-\tilde{v}_{m} \phi_{m}\right)$, corresponding to revenues for new and remanufactured products. A one-day increase in the path from distributor to sales $\left(1 / \mu_{d}, \tau_{d s}\right.$ or $\left.1 / \mu_{s}\right)$ decreases expected profit by a higher amount $\lambda \tilde{P} \alpha+(1-p) \lambda_{r}\left(\tilde{P}_{m} \alpha_{m}-\tilde{v}_{m} \phi_{m}\right)+p \lambda_{r} \tilde{v} \phi$ due to its effect on new returns.

(iii) The delay of returned products to reach the evaluating facility $W_{c e}$. Thus, a one-day increase in the path from consumer to evaluating facility (2) decreases expected profit by $\lambda_{r}\left\{-(\tilde{P} \beta-p \tilde{v} \phi)+(1-p)\left(\tilde{P}_{m} \alpha_{m}-\tilde{v}_{m} \phi_{m}\right)\right\}$. The time-lag for credit issuance to retailers has a positive effect on expected profit. However, the difference in production costs for new returns and the decrease in value for the remanufactured product have negative effects on expected profit.

(iv) The transportation and production delay between the evaluating facility and remanufacturing $W_{c m}-W_{c e}$. Thus, a one-day increase in the path from the evaluating facility to remanufacturing (3) decreases expected profit by $(1-p) \lambda_{r}\left(\tilde{P}_{m} \alpha_{m}-\tilde{v}_{m} \phi_{m}\right)$, corresponding to net revenues for remanufactured products sold in the secondary market.

(v) The delay incurred for transportation and sales in the secondary market $W_{c 2}-W_{c m}$. Thus, a one-day increase in the path from the remanufacturing facility to the secondary market (4) 
decreases expected profit by $(1-p) \lambda_{r} \tilde{P}_{m} \alpha_{m}$, corresponding to sales revenues for remanufactured products sold in the secondary market.

We note that the value of one-day reduction in delays for the reverse network (iii)-(v) depends on the following parameters: return rate $\lambda_{r}$, decay parameters for the remanufactured product price $\alpha_{m}$ and variable cost $\phi_{m}$, proportion of new returns $p$, remanufactured product price $\tilde{P}_{m}$ and variable cost $\tilde{v}_{m}$, variable production cost $\tilde{v}$, and decay parameter for variable production cost $\phi$ (the term $\tilde{P} \beta$ is numerically very small in our experience). These parameters are all drivers of responsiveness in the reverse network. To gain a better intuition, consider the special case where all value decay parameters are equal (this is the case of HP and Bosch, which we study later in §7), which we denote by $\varphi$. Then, the value of one day in the different links of the reverse network (iii)-(v) become $\lambda_{r}\left\{-(\tilde{P} \beta-p \tilde{v} \varphi)+(1-p) \varphi\left(\tilde{P}_{m}-\tilde{v}_{m}\right)\right\},(1-p) \lambda_{r} \varphi\left(\tilde{P}_{m}-\tilde{v}_{m}\right)$, and $(1-p) \lambda_{r} \tilde{P}_{m} \varphi$. In short, ignoring the small term $\tilde{P} \beta-p \tilde{v} \phi$, a day in the reverse network is more valuable if the return rate is higher, fewer new returns are diverted directly into the forward chain, the value decay parameter is higher, the remanufactured product profit margin is higher, and the remanufactured product value is higher. Put it differently, time is important in the reverse network for product returns with high recoverable value, high value decay parameter, and high volume of remanufacturing.

\section{Improving Network Responsiveness}

The preceding analysis demonstrates the monetary benefits of decreasing delays in different parts of the network. It allows for a time-cost analysis of responsive network designs. Actions to improve network responsiveness (see equations (1)-(4)) include increasing the processing rate of returns $\mu_{i}$ at each node (retailer, evaluating and remanufacturing facilities), and decreasing the average transportation times $\tau_{i j}$ (by co-location of facilities, or faster transportation modes). Before analyzing these alternatives, we note that $\Pi$ is a separable function in each delay variable $\mu_{i}$ (that is, 
$\partial^{2} \Pi / \partial \mu_{i} \partial \mu_{j}=0$ for $\left.i \neq j\right)$, and thus a sufficient condition for (8) to be jointly concave in $\mu_{i}$, for all $i$, is that $\partial^{2} \Pi / \partial \mu_{i}^{2}<0$ for all $i$.

\subsection{Increasing Processing Rate of Returns at the Retailers or Evaluating Facilities}

Improving responsiveness $\mu_{r}$ at the retailer requires investments by the manufacturer according to the unit handling cost function $h_{r}\left[\mu_{r}\right]$. At Bosch the returns wait in cages at the retailer until a Bosch sales person makes the disposition and shipment decision. Bosch can increase the processing rate at each retailer by increasing the number of visits, which may require more service personnel. Similarly the manufacturer can also improve the processing rate of returns at the central evaluating facility $\mu_{e}$. This would again involve investments in workforce for parallel processing, or investments in sorting, picking, and routing technology.

To find the optimal level of responsiveness $\mu_{i}^{*}$, we apply the first order condition to (8), recalling that $\mu_{i}, i \in\{r, e\}$ impacts $W_{c e}$ according to (2):

$$
\frac{\partial \Pi}{\partial \mu_{i}}=0 \Rightarrow \frac{\left(-(\tilde{P} \beta-p \tilde{v} \phi)+(1-p)\left(\tilde{P}_{m} \alpha_{m}-\tilde{v}_{m} \phi_{m}\right)\right)}{\left(\mu_{i}^{*}-\lambda_{r}\right)^{2}}=\tilde{h}_{i}^{\prime}\left[\mu_{i}^{*}\right], \quad i \in\{r, e\} .
$$

Sufficient conditions for (8) to be jointly concave (such that the solution to (9) is sufficient for optimality) are that (i) $\tilde{h}_{i}\left[\mu_{i}\right]$ be a convex function (including a linear function which is a reasonable assumption as stated below), and (ii) that $(1-p)\left(\tilde{P}_{m} \alpha_{m}-\tilde{v}_{m} \phi_{m}\right)>\tilde{P} \beta-p \tilde{v} \phi$, that is, remanufacturing margins are higher than the net (negative) impact of the time lag for returns (i.e., difference between time-value of money for credit issuance and production cost lag for new returns), since

$$
\partial^{2} \Pi / \partial \mu_{i}^{2}=-2 \lambda_{r} \frac{\left(-(\tilde{P} \beta-p \tilde{v} \phi)+(1-p)\left(\tilde{P}_{m} \alpha_{m}-\tilde{v}_{m} \phi_{m}\right)\right)}{\left(\mu_{i}-\lambda_{r}\right)^{3}}-\lambda_{r} \tilde{h}_{i}^{\prime \prime}\left[\mu_{i}\right]
$$

which is strictly negative if these two conditions are satisfied.

Now, assume a linear function for the unit handling cost as a function of the processing rate for returns, i.e., $h_{i}\left[\mu_{i}\right]=a_{i} \mu_{i}+b_{i}$. This linear function can be justified because return handling 
operations are labor intensive (Davey 2001). Then, $\tilde{h}_{i}\left[\mu_{i}\right]=\tilde{a}_{i} \mu_{i}+\tilde{b}_{i}$, where $\tilde{a}_{i}=a_{i}\left(1-e^{-\beta T}\right) / \beta$ and a similar expression holds for $\tilde{b}_{i}$. For this linear cost case, (9) yields:

$$
\mu_{i}^{*}=\lambda_{r}+\sqrt{\frac{(1-p)\left(\tilde{P}_{m} \alpha_{m}-\tilde{v}_{m} \phi_{m}\right)-(\tilde{P} \beta-p \tilde{v} \phi)}{\tilde{a}_{i}}}, \quad i \in\{r, e\} .
$$

We note that (10) has the solution form of a classic queuing design problem: find the optimal processing rate at an $\mathrm{M} / \mathrm{M} / 1$ queue that minimizes the expected cost rate (see, e.g., Gross and Harris 1998, p. 304), with waiting cost rate $(1-p)\left(\tilde{P}_{m} \alpha_{m}-\tilde{v}_{m} \phi_{m}\right)-(\tilde{P} \beta-p \tilde{v} \phi)$ and service cost rate $\lambda_{r} \tilde{a}_{i}$. Only a fraction $1-p$ of all returns $\lambda_{r}$ are remanufactured and sold at a revenue of $\tilde{P}_{m}$ with an "interest rate" $\alpha_{m}$. This revenue is decreased by the variable remanufacturing costs $\tilde{v}_{m}$, which also decrease with time (thus waiting decreases costs) at a rate $\phi_{m}$. In addition, the waiting cost rate should be decreased by the time-value of money amount corresponding to delayed credit issuance to retailers $\tilde{P} \beta$, but increased by the difference in variable cost of production for new returns. The optimal return processing rate at either retailer or evaluating facility is not influenced by transportation costs, but it is directly influenced by the remanufactured product margin. Low margins result in designs with a low level of responsiveness. A higher remanufacturing price decay parameter $\alpha_{m}$ and a higher variable cost decay parameter $\phi$ (higher clockspeed) increase the waiting cost rate (numerator in the square root of (10)). This increases processing capacity (lowers the waiting time) leading to a more responsive returns network design, in agreement with Fisher's framework.

A similar analysis can be conducted for the optimal level of responsiveness in the forward distribution network, i.e., $\mu_{i}, i \in\{f, s, d\}$. However, this requires modeling specific costs associated with a level of responsiveness at the factory (increased transportation frequency to the distributor), distributor (more frequent deliveries to retailers), and retailer (advertising, promotion, and pricing), and the focus of this paper is not on forward supply chains. 


\subsection{Increasing Transportation Responsiveness}

Transportation responsiveness in the network can be influenced by design choices such as colocation of facilities or selecting faster transportation. For example, if the firm co-locates the remanufacturing and the evaluating facilities, then $\tau_{e m}=0$, and profits increase by $\tau_{e m}(1-p) \lambda_{r}\left(\tilde{P}_{m} \alpha_{m}-\tilde{v}_{m} \phi_{m}\right)$, according to (8).

Regarding transportation modes, each of the unit cost parameters $\tilde{c}_{i j}\left(\right.$ or $c_{i j}$ ) is a function of transportation time $\tau_{i j}$, that is, $\tilde{c}_{i j}\left[\tau_{i j}\right]$. Consider using the design option of moving from ground to air transportation. The savings may be determined by computing the monetary value of a one-day delay reduction on that corresponding arc of the network (§4) and multiplying by the number of days saved. These savings are compared against the additional transportation costs of going from ground to air.

\section{Preponement: Decentralized Returns Network}

In this section we analyze the drivers of alternative structural designs. Figure 3 represents the typical centralized industrial returns evaluation and credit issuance network design where all commercial returns are shipped to a central facility for economies of scale. The benefits in economies of scale for evaluation and credit issuance are clear. Alternatively, consider an innovative design where new returns are sorted and immediately re-stocked at the retailer. This decentralized design reduces transportation costs, utilization at the central evaluation facility, and consequently the delay of other returned products. This, in turn, increases their value in the secondary market. We call this decentralized design concept preponement (or early product differentiation) to distinguish it from postponement (or late product differentiation), typical in forward supply chains. Both HP and Bosch are considering the use of preponement.

With preponement, additional work is required at the retailer to handle and re-package the returns. The retailer may need to hire and train workers to perform this task and maintain extra 
packaging material at the stores. For the retailer to agree to this, proper incentive schemes should be offered by the manufacturer. Alternately, the manufacturer could periodically send workers to the retailer's site to handle the returns, similar to Vendor Management Inventory (VMI). This alternative may prove easier to implement and control.

The decentralized design network is shown in Figure 4. We use a superscript $p$ to denote, when different, parameters for this proposed preponement network. The flow rates between each pair of nodes are $\lambda_{r s}^{p}=p \lambda_{r}, \quad \lambda_{r e}^{p}=(1-p) \lambda_{r}, \quad \lambda_{d s}^{p}=\lambda+(1-p) \lambda_{r}$, and $\lambda_{e d}^{p}=0$; other flows are defined as before.

Figure 4: Closed-loop supply chain with preponement: new returns handled at retailer

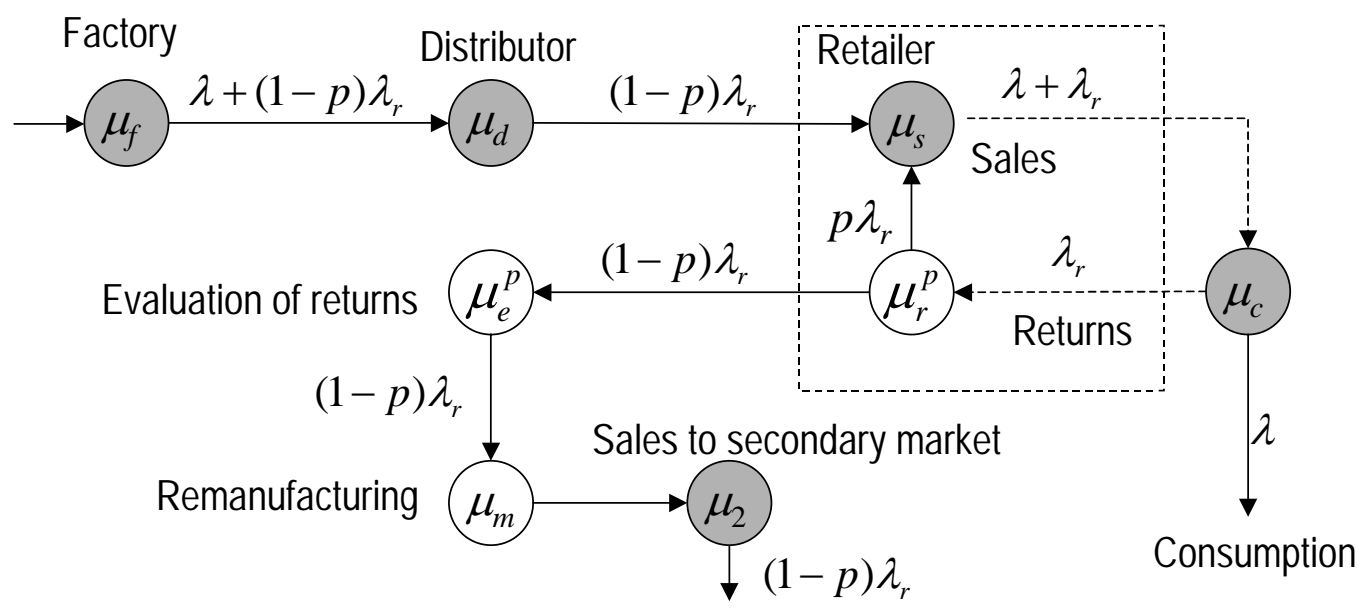

Note: Blank and shaded nodes are modeled as M/M/1 and M/G/o queues, respectively

An analysis similar to that performed in $\$ 4$ provides the total expected discounted profit over the steady state period of the lifecycle:

$$
\begin{aligned}
\Pi^{p} & \approx \lambda(\tilde{P}-\tilde{v})+(1-p) \lambda_{r}\left(\tilde{P}_{m}-\tilde{v}_{m}-\tilde{v}\right)-\sum_{(i, j)} \lambda_{i j}^{p} \tilde{c}_{i j}-\lambda_{r} \tilde{h}_{r}^{p}\left[\mu_{r}^{p}\right]-(1-p) \lambda_{r} \tilde{h}_{e}^{p}\left[\mu_{e}^{p}\right] \\
& -\frac{1}{\mu_{s}} p \lambda_{r} \tilde{v} \phi-W_{f s}\left\{\lambda \tilde{P} \alpha+(1-p) \lambda_{r}\left(\tilde{P}_{m} \alpha_{m}-\tilde{v}_{m} \phi_{m}\right)\right\} \\
& -W_{c e}^{p}(1-p) \lambda_{r}\left\{-\tilde{P} \beta+\left(\tilde{P}_{m} \alpha_{m}-\tilde{v}_{m} \phi_{m}\right)\right\}+\left(\frac{1}{\mu_{c}}+\frac{1}{\mu_{r}^{p}-\lambda_{r}}\right) p \lambda_{r}(\tilde{P} \beta-\tilde{v} \phi) \\
& -\left(\tau_{e m}+\frac{1}{\mu_{m}-(1-p) \lambda_{r}}\right)(1-p) \lambda_{r}\left(\tilde{P}_{m} \alpha_{m}-\tilde{v}_{m} \phi_{m}\right)-\left(\tau_{m 2}+\frac{1}{\mu_{2}}\right)(1-p) \lambda_{r} \tilde{P}_{m} \alpha_{m}
\end{aligned}
$$


We do not include in (11) the incentive, if any, paid by the manufacturer to the retailer, or the extra VMI cost. Our analysis focuses on the total benefits of the proposed network. This benefit can be weighed against these extra monetary incentives or costs. Relative to the centralized network of Figure 3, the only delay that is different in the preponement network of Figure 4 is the delay for the returned product between the consumer and the evaluating facility $W_{c e}^{p}$. This is a result of reduced flow at the evaluating facility:

$$
W_{c e}^{p}=1 / \mu_{c}+\frac{1}{\mu_{r}^{p}-\lambda_{r}}+\tau_{r e}+\frac{1}{\mu_{e}^{p}-(1-p) \lambda_{r}} .
$$

Taking the difference $(11)-(8)$, and defining $\Delta_{i}$ as the difference in waiting times at node $i$ between the existing and proposed network (e.g., $\Delta_{r}=\left(\mu_{r}-\lambda_{r}\right)^{-1}-\left(\mu_{r}^{p}-\lambda_{r}\right)^{-1}$ ), we state, after some algebra, the monetary benefits of the proposed decentralized network:

$$
\begin{aligned}
\Pi^{p}-\Pi= & \lambda_{r}\left\{(1-p)\left(\tilde{P}_{m} \alpha_{m}-\tilde{v}_{m} \phi_{m}\right)\left(\Delta_{r}+\Delta_{e}\right)\right. \\
& -\tilde{P} \beta\left\{\Delta_{r}+\Delta_{e}+p\left(\tau_{r e}+\frac{1}{\mu_{e}^{p}-(1-p) \lambda_{r}}\right)\right\} \\
& +p \tilde{v} \phi\left(\tau_{e d}+\frac{1}{\mu_{d}}+\tau_{d s}+\Delta_{r}+\Delta_{e}+\tau_{r e}+\frac{1}{\mu_{e}^{p}-(1-p) \lambda_{r}}\right) \\
& +p\left(\tilde{c}_{d r}+\tilde{c}_{r e}+\tilde{c}_{e d}\right)+ \\
& \left.+\left(\tilde{h}_{e}\left[\mu_{e}\right]-(1-p) \tilde{h}_{e}^{p}\left[\mu_{e}^{p}\right]\right)+\left(\tilde{h}_{r}\left[\mu_{r}\right]-\tilde{h}_{r}^{p}\left[\mu_{r}^{p}\right]\right)\right\} .
\end{aligned}
$$

The terms in (13) indicate, respectively:

(i) The increased value obtained from remanufactured products since they reach the secondary market earlier (see below),

(ii) the decrease in profit since there is no time lag for credit issuance for new returns in the preponement network,

(iii) the savings in variable production cost for new returns since they are being re-sold faster,

(iv) the decrease in transportation cost for new returns in the preponement network, and

(v) the difference in handling cost at the retailer and evaluating facility. 
The return rate $\lambda_{r}$ multiplies the entire right-hand side of (13), that is, $\lambda_{r}$ is a scaling parameter for the benefits of preponement. Drivers of the attractiveness of preponement design include, as before, decay parameters for the remanufactured product price $\alpha_{m}$ and variable cost $\phi_{m}$, proportion of new returns $p$, remanufactured product price $\tilde{P}_{m}$ and variable cost $\tilde{v}_{m}$, variable production cost $\tilde{v}$, the decay rate for variable production cost $\phi$, transportation and handling costs (again, the term $\tilde{P} \beta$ is numerically very small in our experience). The term $\Delta_{r}+\Delta_{e}$ is a small number in practice, and consequently the first term of (13) is small relative to the other terms. As a result, we develop two general propositions providing insights into the other three major drivers of attractiveness of the preponement design, i.e., the continuous-time variable production cost decay parameter $\phi$, the variable production cost $\tilde{v}$, and the proportion of new returns, $p$.

Proposition 1: The benefits of preponement $\Pi^{p}-\Pi$ are increasing in $\phi$ and in $\tilde{v}$ if

$$
\left(\tau_{e d}+\frac{1}{\mu_{d}}+\tau_{d s}+\Delta_{r}+\Delta_{e}+\tau_{r e}+\frac{1}{\mu_{e}^{p}-(1-p) \lambda_{r}}\right) \geq 0 \text {. }
$$

The proof of Proposition 1 is immediate and omitted. Proposition 1 implies that there is a $\phi *$ such that a decentralized (preponement) network design is preferred if $\phi \geq \phi *$; else a centralized network is appropriate. Condition (14) is very weak; it only requires that the time necessary to restock a new return is lower in the preponement network. A similar result can be derived for the other design driver $p$ :

Proposition 2: The benefits of preponement $\Pi^{p}-\Pi$ are increasing in $p$ under (14), $\tilde{v} \phi \geq \tilde{P} \beta$, and if the remanufactured product margin savings (as a result of lower delays to reach the secondary market) are outweighed by all other preponement benefits.

Proof: Simple algebra shows that

$$
\begin{aligned}
\left(\Pi^{p}-\Pi\right) p^{-1} \lambda_{r}^{-1}= & (\tilde{v} \phi-\tilde{P} \beta)\left(\tau_{e d}+\frac{1}{\mu_{d}}+\tau_{d s}+\Delta_{r}+\Delta_{e}+\tau_{r e}+\frac{1}{\mu_{e}^{p}-(1-p) \lambda_{r}}\right)+\tilde{P} \beta\left(\tau_{e d}+\frac{1}{\mu_{d}}+\tau_{d s}\right) \\
& +\left(\tilde{c}_{d r}+\tilde{c}_{r e}+\tilde{c}_{e d}+\tilde{h}_{e}^{p}\left[\mu_{e}^{p}\right]\right)-\left(\Delta_{r}+\Delta_{e}\right)\left(\tilde{P}_{m} \alpha_{m}-\tilde{v}_{m} \phi_{m}\right) .
\end{aligned}
$$


The last term represents the remanufactured product margin savings and represents the only negative term in the partial derivative of $\Pi^{p}-\Pi$ with respect to $p$. This negative term is relatively small because in practice, $\Delta_{r}+\Delta_{e}$ is a small number, particularly when compared with the transportation and handling cost savings. $\square$

Proposition 2 implies that there exists a $p^{*}$ such that a decentralized network is preferred if $p \geq$ $p^{*}$. The (weak) condition $\tilde{v} \phi \geq \tilde{P} \beta$ implies that the manufacturer's time-value benefits of delaying credit issuance for new returns, which are absent in the preponement scenario, are outweighed by savings in new returns variable costs. Alternatively the manufacturing value decay parameter should be significantly higher than the discount factor.

Assuming the same linear unit handling cost function as before $h_{i}^{p}\left[\mu_{i}^{p}\right]=a_{i}^{p} \mu_{i}^{p}+b_{i}^{p}$, we can use a similar analysis, as before, to find the optimal processing capacities at the retailer and evaluating facility. Then,

$$
\begin{gathered}
\mu_{r}^{p^{*}}=\lambda_{r}+\sqrt{\frac{(1-p)\left(\tilde{P}_{m} \alpha_{m}-\tilde{v}_{m} \phi_{m}\right)-(\tilde{P} \beta-p \tilde{v} \phi)}{\tilde{a}_{r}^{p}}}, \text { and } \\
\mu_{e}^{p^{*}}=(1-p) \lambda_{r}+\sqrt{\frac{\tilde{P}_{m} \alpha_{m}-\tilde{v}_{m} \phi_{m}-\tilde{P} \beta}{\tilde{a}_{e}^{p}}}
\end{gathered}
$$

It is reasonable to expect that the preponement design option will have higher variable handling costs at the retailer (because of extra tasks) and lower variable handling costs at the evaluation facility (because of less tasks), i.e., $\tilde{a}_{r}^{p} \geq \tilde{a}_{r}$ and $\tilde{a}_{e}^{p} \leq \tilde{a}_{e}$. Thus, $\mu_{r}^{p^{*}} \leq \mu_{r}^{*}$, since (15) only differs from (10) in the denominator inside the square-root. Comparing $\mu_{e}^{p^{*}}$ and $\mu_{e}^{*}$ is not as straightforward since the lower value of $\tilde{a}_{e}^{p}$ tends to increase $\mu_{e}^{p^{*}}$ relative to $\mu_{e}^{*}$. However, the lower flow of returns $(1-p) \lambda_{r}$ through the evaluation facility tends to decrease $\mu_{e}^{p^{*}}$ relative to $\mu_{e}^{*}$. For larger values of $p$, it is clear that the lower flow effect will tend to dominate (16). In the limit, when $p=1, \mu_{e}^{p^{*}}=0$, and $\mu_{e}^{p^{*}} \leq \mu_{e}^{*}$ clearly holds. 
In the next section, we apply our theoretical results to HP and Bosch, and perform a sensitivity analysis on the key drivers of responsiveness and preponement design alternatives.

\section{Application of Model Results}

In this section, we apply the theoretical results to actual data from HP and Bosch. The main differences in parameter values for the two firms are product value, life cycle length, value decay parameters, demand, and return rates. Many of the parameter values are approximately equal for both firms, and for reasons of confidentiality, we use common representative numbers assumed fixed throughout the numerical analysis: a $25 \%$ gross margin for new products $(v[0] / P[0]=0.75)$, a $15 \%$ price discount for the remanufactured product relative to the new product $\left(P_{m}[0] / P[0]=0.85\right)$, and a $5 \%$ yearly discount rate $\left(\beta=1.4 \times 10^{-4}\right)$. We performed a sensitivity analysis on these parameters but chose to omit the results since the analysis does not add additional insights.

The price decay parameters for remanufactured and new products are approximately the same ( $\alpha=\alpha_{m}$ ) within each company. Although different components decay at different rates, we estimate that the overall manufacturing cost of a product decays at a rate roughly equal to the final product's price decay, that is, $\alpha=\alpha_{m}=\phi=\phi_{m}$. For this reason, we use a single value decay parameter, $\varphi$. This assumption brings parsimony to the analysis without compromising insights or the order of magnitude of the results. The units of analysis throughout are a full truckload of returned products and a time of one day.

\subsection{Hewlett-Packard Inkjet Printers}

A delivery truck contains an average of 250 inkjet printers. The median price of an HP inkjet printer is $\$ 200$, and thus $P[0]=250 \cdot \$ 200=\$ 50,000$. For inkjets, $T=395$ days (13 months), returns are $5 \%$ of net sales, so $\lambda_{r} / \lambda=0.05$. The daily return rate averages $\lambda_{r}=6.67$ trucks, $p=1 / 3$, and the common value decay parameter is $\varphi=1.43 \times 10^{-3}$ (1\% per week). The remanufacturing cost is approximately $7.5 \%$ of the retail price of a new product, that is, $v_{m}[0] / P[0]=0.075$. 
Our analysis shows the values of a one-day reduction between different facilities in the returns network: $\$ 35,069$ between the evaluating facility and distributor, $\$ 93,797$ between the customer and evaluating facility, $\$ 72,475$ between the evaluating facility and remanufacturing, and $\$ 79,489$ between remanufacturing and the secondary market, respectively. Managers indicate that lead-time reduction in the forward network is currently being pursued at the level of hours, not days. However, opportunities for significantly reducing lead-times abound in HP's reverse supply chain. The sojourn time at retailers, delay between retailers and process completion at the evaluating facility, and delay between the evaluating facility and remanufacturing completion average 10, 8 and 40 days respectively. We analyze each opportunity separately below.

First, consider the retailer returns processing capacity. For a more realistic analysis, consider multiple retailers. For example, using 1,000 identical retailers with an average sojourn time of 10 days implies $1 /\left(\mu_{r}-\lambda_{r} / 1000\right)=10$, or a current return processing capacity of $\mu_{r}=0.1067$. If we decrease the average sojourn time by two days (and save approximately $\$ 180,000$ ) with the same rate of returns, this implies $\mu_{r}=0.1317$, or a $23 \%$ increase in returns processing capacity. To find the optimal processing capacity (10), we require an accurate estimate of handling costs at the retailers. ${ }^{1}$

Second, consider transportation to, and sojourn time at, the evaluating facility. Managers at HP believe that this delay can be cut from its current 8 days to 2 days, resulting in lifecycle savings of approximately half a million dollars. Finally, the largest opportunity lies in the long delays for shipment from the evaluating facility until completion of the remanufacturing operation, which is currently 40 days. Management believes that a reasonable goal for this delay is 20 days. Achieving this goal implies a lifecycle savings of $\$ 1.45$ million. We note that our estimates are conservative, since we do not explicitly account for savings in working capital and the corresponding reduction in inventory holding costs. Thus, it appears worthwhile for HP to consider a responsive network design.

\footnotetext{
${ }^{1}$ We note that the conditions (i) and (ii) for optimality of (10), which are described in the paragraph after (9), are both satisfied. Condition (i) is naturally satisfied because (10) assumes linear handling costs. Condition (ii) is satisfied because $(1-p)\left(\tilde{P}_{m} \alpha_{m}-\tilde{v}_{m} \phi_{m}\right)=10,866$, which is always greater than $\tilde{P} \beta-p \tilde{v} \phi$; this is because $\tilde{P} \beta-p \tilde{v} \phi \leq \tilde{P} \beta=2,061$.
} 
We estimate the current lifecycle value of preponement for HP (13) to be roughly $\$ 4.1$ million, using the following assumptions: (i) retailers are situated at an average of 1000 miles from the evaluating facility; (ii) the truckload transportation rate is $\$ 1.3 / \mathrm{mile}^{2}$; (iii) the likely increase in handling cost at the retailer is offset by the likely decrease in handling cost at the evaluating facility, and, consequently, the difference in total handling costs (across retailer and evaluating facility) between the current and preponement scenarios is negligible, and (iv) the difference in waiting times between the current and preponement scenarios is negligible (i.e., $\Delta_{r}+\Delta_{e}=0$ ). Of these $\$ 4.1$ million, roughly $20 \%$ are related to the time value savings in variable costs for new returns (third term in (13)), $81 \%$ are related to savings in transportation costs (fourth term in (13)); the second negative term in (13) is negligible at $-1 \%$; the first and last terms in (13) are zero by our assumptions. It should be clear from these rough-cut calculations that HP has a keen interest in a more detailed analysis of the practical implications of the preponement option.

\subsection{Bosch Power Tools}

A delivery truck contains an average of 500 power tools. The average price of a Bosch power tool is $\$ 50$, and thus $P[0]=\$ 25,000$. For power tools, $T=1,675$ days (55 months). Return rate is $2.6 \%$ of net sales $\left(\lambda_{r} / \lambda=0.026\right), \lambda_{r}=1.5, p=0$, and the common value decay parameter is $\varphi=$ $3.5 \times 10^{-4}$ (1\% per month). The remanufacturing cost is approximately $7.5 \%$ of the retail price of a new product, that is, $v_{m}[0] / P[0]=0.075$.

The value of reducing one day between the customer and evaluating facility (which is colocated at the new products factory) $W_{c e}$ is $\$ 5,624$. The value of one-day reduction between the evaluating facility and remanufacturing $W_{c m}-W_{c e}$, and between remanufacturing and the secondary market are $\$ 11,623$ and $\$ 12,748$, respectively. Given these results, is appears that Bosch should consider an efficient reverse supply chain network to handle returns. The sensitivity analysis for Bosch, similarly to HP's, yields the same conclusions and is omitted.

\footnotetext{
${ }^{2}$ This estimate of transportation rate is based on a US DOT report http://ops.fhwa.dot.gov/freight/documents/bts.pdf
} 
At Bosch, preponement is a much less viable option than at HP. This is easily explained by the major drivers: a much smaller return rate containing very few new returns and therefore smaller potential transportation cost savings, and a considerably smaller value decay over time yielding even smaller savings in variable production costs for new returns. Setting up decentralized low touch remanufacturing facilities (thereby approximating the idea of preponement) would be relatively costly as well, even if all $40 \%$ of non-defective returns (table 2) could be handled decentrally (and thereby avoid larger transportation costs).

\subsection{Sensitivity Analysis}

In order to gain general insights in the drivers of reverse supply chain design, we performed a sensitivity analysis. Using the base numbers for HP's product value, life cycle length, and demand volume, we vary the values for the key drivers of reverse supply chain design: the return rate $\lambda_{r}$, the common value decay parameter $\varphi$, the proportion of new returns $p$, and the remanufactured product profit margin $P_{m}[0]-v_{m}[0]$ (since $P_{m}[0]=0.85 P[0]$ is fixed, we vary $v_{m}[0] / P[0]$ ). We also examine the effect of changes in the new product value $P[0]$, and in the lifecycle length $T$ (demand volume does not impact the reverse network design.) We selected the range for these parameters based on representative values for products in a wide range of industries. That is, $\lambda_{r} \in[0,15]$, corresponding to a return rate between $0 \%$ and $12 \%$ of net sales; $\varphi \in[0.0001,0.004]$, corresponding to monthly value decay rates between $0.3 \%$ and $12 \% ; p \in[0,0.75] ; v_{m}[0] / P[0] \in[0.025,0.50]$, corresponding to a remanufacturing cost between $2.5 \%$ and $50 \%$ of the new product price, $P[0] \in$ [25000, 250000], corresponding to a unit product price between $\$ 100$ and $\$ 1000$; and $T \in[180$, 1675], corresponding to a lifecycle length between 6 and 55 months. The analyses assume that every unit decrease in returns results in one more unit of net sales, that is, $\lambda+\lambda_{r}$ is kept constant at 140 truckloads per day. We focus on the value of a one-day reduction between the evaluating facility and remanufacturing completion, since this segment has the largest delays. Additional sensitivity 
analyses were performed for the other segments of the reverse supply chain (e.g., customer and evaluating facility) and the results were similar to the ones discussed here and therefore omitted.

Figure 5 shows the value of one-day time reduction between the evaluating facility and remanufacturing completion as a function of the return rate $\lambda_{r}$ and the time value decay parameter $\varphi$. The marginal value of time becomes important for higher values of the return rate. In those cases, e.g., companies like HP, there are substantial benefits to be gained from considering a responsive reverse supply chain design. Conversely, when return rates are low a cost-efficient reverse supply chain is favored, even when the marginal value of time is high. Since both returns and the marginal value of time are increasing at a rapid pace globally and across industries, managers need to be aware of the growing potential benefits of adopting a responsive reverse supply chain design.

Figure 5 also shows that when there is a high product value coupled with a high value decay rate, there are significant benefits to be gained from a responsive, reverse supply chain. As discussed before, $\lambda_{r}$ and $P[0]$ are scale parameters; the benefit of a one-day reduction from remanufacturing to the secondary market increases linearly with these scale parameters. The marginal value of time $\varphi$ becomes important for high values of the return rate and product value.

Figure 6 shows that, for those companies where both return rates and time value decay are considerable (using HP's 5\% return rate), the proportion of new returns has a negative linear impact on the potential value of a one-day time reduction between remanufacturing and sales at the secondary market. However, as mentioned previously, this percentage is a driver of a decentralized preponement returns network. Figure 6 (right), shows that the value of a one-day reduction increases at a decreasing rate with the lifecycle length $T$; this is because of discounting and decreasing product values with time. Figure 7 shows the value of one-day between evaluating facility and remanufacturing completion as a function of remanufacturing variable cost; the impact is linear and more significant at high value decay rates. 
Finally, Figure 8 shows the value of preponement as a function of the proportion of new returns. The preponement value is more sensitive to $p$ because approximately $81 \%$ of the value of preponement for HP is derived from savings in transportation costs for new returns as compared to $20 \%$ derived from the time value-mostly from variable cost savings in new returns-captured by the value decay parameter. It should also be clear from Figure 8 and (13) that if return policies become even more lenient, i.e. both return rate and percentage new returns increase, and clockspeed continues to increase as well, preponement solutions involving close collaboration with channel partners may become imperative in order to maintain profitability in small margin businesses. In other words, many of today's centralized returns handling networks may have to be reengineered in the future.

Figure 5: Value (\$) of One-Day Reduction Between Evaluating Facility and Remanufacturing Completion as a Function of Value Decay Parameter, Return Rate (left), and Product Value (right)
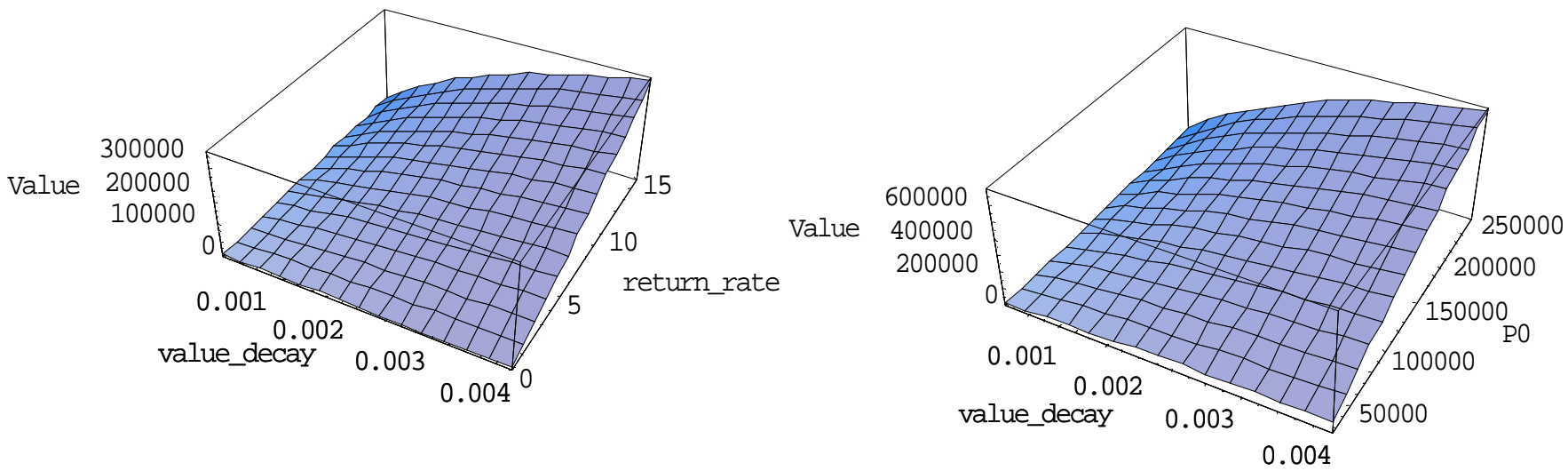
Figure 6: Value (\$) of One-Day Reduction Between Evaluating Facility and Remanufacturing Completion as a Function of Value Decay Parameter, Proportion of New Returns (left), and Lifecycle Length (right)
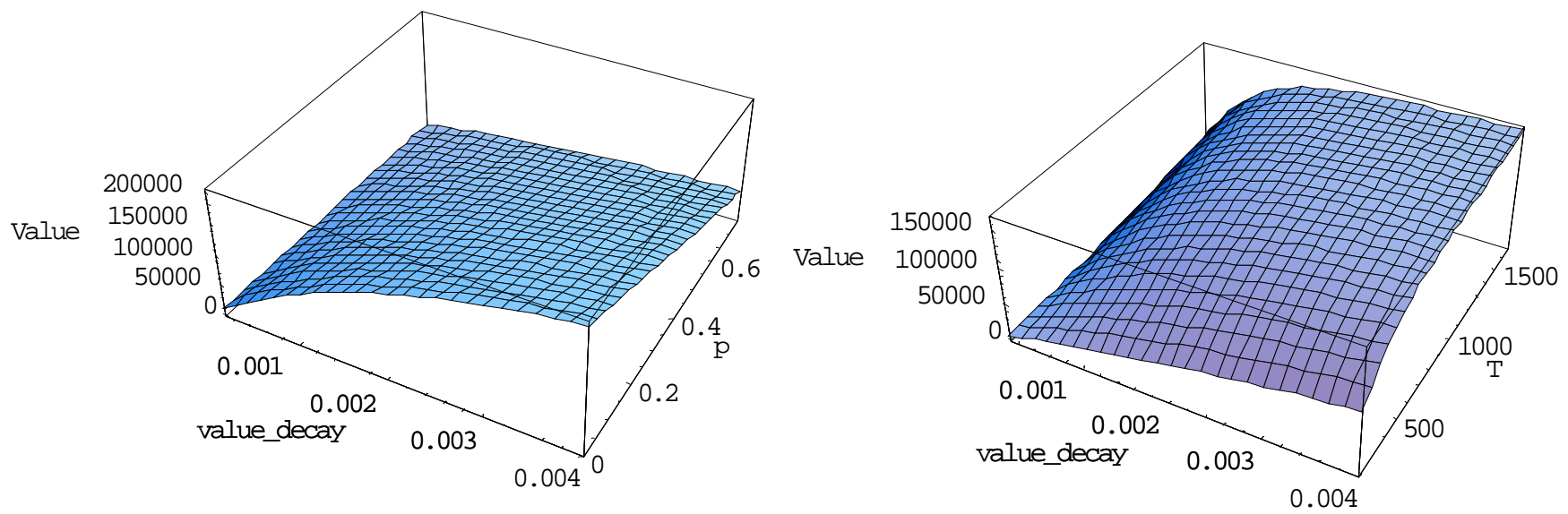

Figure 7: Value (\$) of One-Day Reduction Between Evaluating Facility and Remanufacturing Completion as a Function of Value Decay Parameter, and Remanufacturing Variable Cost;

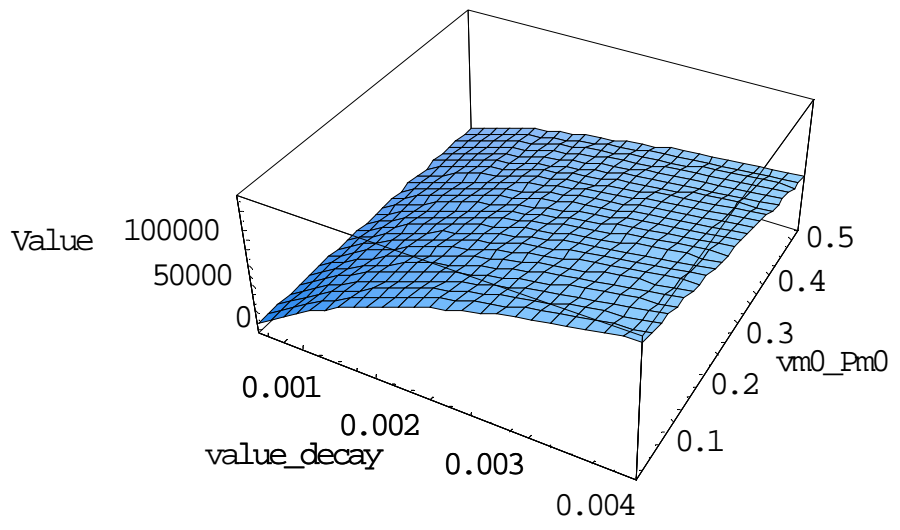




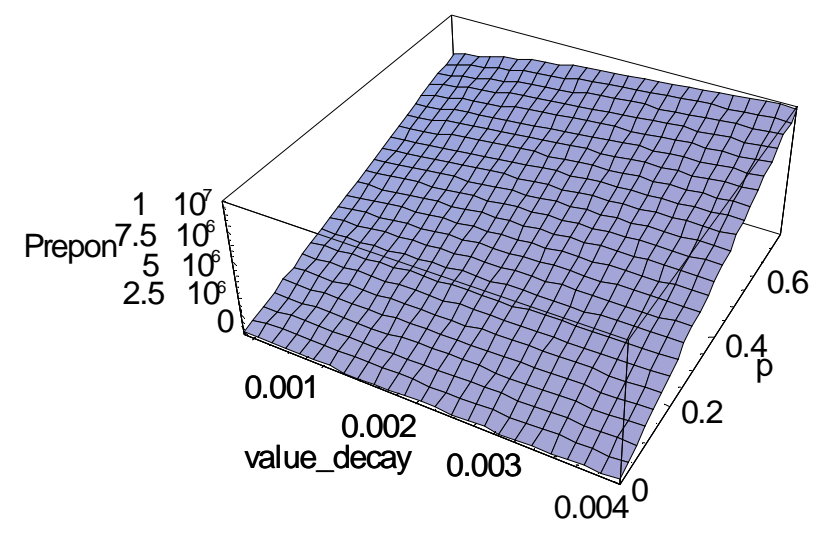

\section{Conclusion}

Many reverse supply chain networks are designed to minimize logistics costs through central product returns depots. In accordance with Fisher's (1997) framework for forward supply chains, we show through a simple queuing network model and data from HP and Bosch, that cost-efficient reverse supply chain networks are not always appropriate. We explicitly model the decay in value for components and finished products for both primary and secondary markets. Key drivers of reverse supply chain responsiveness are the return rate, time value decay parameters, percentage of new returns, and returned product recoverable value. Responsive reverse supply chains are favored for products with high return rates, considerable recoverable value, and high value decay over time, especially if the proportion of new returns is low (indicating a high percentage of products requiring remanufacturing).

Focusing on the reverse supply chain network, we find the optimal level of return handling capacity at the retailer and evaluating facility, as well as the impact of choosing different transportation modes with different levels of responsiveness. Using data from HP inkjet printers, we show that reducing one day in the average delay encountered by the returned product in the reverse supply chain network increases life-cycle profits by approximately $\$ 80,000$. This is significant considering the ample opportunities for reducing delays. Data from Bosch power tools tells a different story. Consumer power tools have lower and relatively stable prices, therefore the benefit of 
reducing time in the reverse supply chain network is smaller. This shows the need to focus on efficiency and not responsiveness.

We also analyze the benefits of preponement-having returns sorted at the retailer and routed to the appropriate disposition option, a practice that decreases extra transportation and handling costs, and puts new returns (or low-touch returns) back on the shelves much faster. Preponement becomes interesting for products combining a high value of time combined with a considerable rate of return containing many unused or hardly used products, as is the case for some of HP's product lines.

Process knowledge on commercial returns in industry is still immature, as reflected by a lack of frameworks, models and insights. Decision makers are confronted with the problem of incomplete data on these processes. Therefore, it would be useful to conduct empirical studies on return profiles, decay functions and other parameters.

All of these alternatives assume that the return rate is fixed. The firm may also take actions aimed at reducing the return rate. As an example, the firm may decrease the proportion of new returns through better education of sales personnel at the retailers, e.g., informing customers about common installation issues, which avoids new returns because the customer wasn't able to install the product. Another possibility is to improve product design to decrease the percentage of defective products, which is not likely to impact convenience or new returns, but will decrease the return rate, since defective products do constitute a small percentage of returns- $20 \%$ in the case of HP.

\section{References}

Andel, T., M. Aichlmayr. 2002. Turning returns into cash. Transportation \& Distribution 43(8) 2939.

Blackburn, J.D. 2001. Limits of Time-Based Competition: Strategic Sourcing Decisions in Make-toStock Manufacturing. Owen Graduate School of Management Working Paper \#01-19, Vanderbilt University.

Blackburn, J.D. 1991. Time-Based Competition: The Next Battleground in American Manufacturing. Business One Irwin, Homewood IL, USA. 
Blackburn, J.D., V.D.R. Guide, Jr., G.C. Souza, L.N. Van Wassenhove, 2004. Reverse supply chains for commercial returns. California Management Review 46(2), 6-22.

Choi, T., D. Li, H. Yan, 2004. Optimal Return Policy for Supply Chain with e-marketplace. Int. J. Production Economics 88, 205-227.

Davey, S. 2001. Personal communication with the authors. World wide product returns manager, Inkjet Products Group, Hewlett-Packard Company.

Davis, S., E. Gerstner, M. Hagerty. 1995. Money back guarantees in retailing: Matching products to consumer tastes. Journal of Retailing 71, 7-22.

Feitzinger, E., H. Lee. 1997. Mass Customization at Hewlett-Packard: The Power of Postponement. Harvard Business Review, 75(1), 116-121.

Fine, C. 1998. Clockspeed: Winning Industry Control in the Age of Temporary Advantage. Perseus Books, Reading, MA.

Fisher, M. 1997. What is the right supply chain for your product? Harvard Business Review, 75(2) 83-93.

Fleischmann, M. 2001. Quantitative models for reverse logistics. Lecture Notes in Economics and Mathematical Systems, Volume 501, Springer-Verlag, Berlin.

Gross, D., and C. Harris. 1998. Fundamentals of Queuing Theory. Wiley Interscience, New York, NY.

Guide, Jr. V.D.R. 2000. Production planning and control for remanufacturing. Journal of Operations Management 18 467-483.

Guide, Jr. V.D.R., R. Teunter, L.N. Van Wassenhove. 2003. Matching supply and demand to maximize profits in remanufacturing. Manufacturing \& Service Operations Management 5 303-316.

Guide, Jr. V.D.R., L.N. Van Wassenhove (eds.). 2003. Business Aspects of Closed-Loop Supply Chains. Carnegie Mellon University Press, Pittsburgh PA USA.

Guide, Jr. V.D.R., L.N. Van Wassenhove. 2001. Managing product returns for remanufacturing. Production and Operations Management 10 142-155.

Helbig, Barbara. 2002. Personal communication with the authors. Solution and services manager, Equipment Management and Remarketing, Hewlett-Packard GmbH.

Lee, H.L.,S. Whang. 1999. Decentralized Multi-Echelon Supply Chains: Incentrives and Information. Management Science, 45 (5) 633-640.

Lee, H.L., C.S. Tang. 1997. Modeling the Costs and Benefits of Delayed Product Differentiation. Management Science, 43 (1) 40-53. 
Mendelson, H., R. R. Pillai. 1999. Industry clockspeed: Measurement and operational implications, Manufacturing \& Service Operations Management 1 1-20.

Padmanabhan, V., I. Png. 1997. Manufacturer's returns policies and retail competition. Marketing Science 17 81-94.

Padmanabhan, V. I. Png. 1995. Returns policies: Make money by making good. Sloan Management Review 37(1) 65-72.

Pasternack, B. 1985. Optimal pricing and return policies for perishable commodities. Marketing Science 4 166-176.

Stock, J., T. Speh, H. Shear. 2002. Many happy (product) returns. Harvard Business Review 80(7) 16-17.

Swaminathan, J.M, S.R. Tayur. 2003. Models for Supply Chains in E-Business. Management Science 49 (10) 1387-1406.

Toktay, B., L. Wein, S. Zenios. 2000. Inventory management of remanufacturable products. Management Science 46 1412-1426.

Tsay, A. 2001. Managing retail channel overstock: Markdown money and return policies. Journal of Retailing 77 457-492.

Valenta, R. 2002. Personal communication with the authors. Director, Product Service, Robert Bosch Tool Corporation.

Williams, J. 1992. How sustainable is your competitive advantage? California Management Review 34(3) 29-51.

Wolman, H. 2003. Personal communication with the authors. Reconditioned tool business manager, Robert Bosch Tool Corporation.

Wood, S. 2001. Remote purchase environments: The influence of return policy leniency on two-stage decision processes. Journal of Marketing Research XXXVIII 157-169. 